\title{
Overburden Failure Associated with Mining Coal Seams in Close Proximity in Ascending and Descending Sequences Under a Large Water Body
}

\author{
Dingyang Zhang ${ }^{1} \cdot$ Wanghua Sui $^{2}\left[\cdot\right.$ Jiawei Liu $^{1}$
}

Received: 16 March 2017 / Accepted: 1 November 2017 / Published online: 10 November 2017

(C) The Author(s) 2017. This article is an open access publication

\begin{abstract}
We investigated differences of overburden failure induced by mining multiple seams in ascending and descending sequences under a large water body. A case study that involves mining in an ascending sequence was the Beizao coal mine, which is under the Bohai Sea, and one that involves mining in a descending sequence was the Cuizhuang coal mine, which is under Weishan Lake. Using numerical simulations with the same geological conditions as the in-situ measurements, the effects of different interburden thicknesses on mining were compared. The results showed that the ratios of the heights of waterconducting fractured and caving zones to the cutting height both increased as the interburden thickness was reduced. An ascending sequence is recommended where there is a thin interburden and thin bedrock, and where the mining seams obviously interact. The descending sequence is recommended where there is no apparent interaction between
\end{abstract}

Electronic supplementary material The online version of this article (https://doi.org/10.1007/s10230-017-0502-0) contains supplementary material, which is available to authorized users.

Wanghua Sui

suiwanghua@cumt.edu.cn

Dingyang Zhang

dingyangjs@126.com

Jiawei Liu

ljwcumt@126.com

1 School of Resources and Geosciences, China University of Mining and Technology, 1 University Rd (Daxuelu), Xuzhou 221116, Jiangsu, China

2 School of Resources and Geosciences, State Key Laboratory for Geomechanics and Deep Underground Engineering, China University of Mining and Technology, 1 University Rd (Daxuelu), Xuzhou 221116, Jiangsu, China the seams. Both will produce a relatively small water-conducting fractured zone.

Keywords Overburden failure interactions - Multiple coal seam mining - Water-conducting fractured zone · Mining sequence

\section{Introduction}

The consumption of coal in China has increased and the Silk Road initiative will further increase the demand for coal ( $\mathrm{Li}$ et al. 2015, 2017), posing potentially significant impacts to the environment and human health (Li et al. 2016; Wu and Sun 2016). Coal mining in China has caused serious environmental pollution and safety problems in mining areas (Li et al. 2013). One aspect of this is that coal seams that are in close proximity (two adjacent coal seams or multiple coal seams separated by thin layers of interburden) are increasingly being mined. There are now many such coal mines, and some of these are found at deep depth or under water bodies. However, this is not just a problem in China. In the US, nearly $68 \%$ of the total mineable coal resources are found in coal seams in close proximity (Chekan and Listak 1993). Therefore, it is important to examine the heights of overburden failure when such coal seams are mined to learn how best to extract the coal safely.

Regardless of the mining method, there are commonly four kinds of mining sequences used in multiple seam mining: descending, ascending, random sequences, and simultaneous (Akinkugbe 2004; Zipf 2005). When mining two coal seams in China, our focus is on descending and ascending sequences of extraction. Both result in mining interactions due to the effects of full extraction, and frequently involve the tensile failure of the affected mine roof. Supplemental 
Fig. 1 shows the two sequences. The descending sequence of extraction is when the upper seam is mined out before the lower seam, while the ascending sequence is when the lower seam is mined first (Akinkugbe 2004; Zipf 2005).

The damage to overburden by mining is far greater than that to the floor. Thus, mining the upper seam first will induce fewer effects on the lower seam and the interburden layers, which form the roof of the lower seam. There is also better control of the interaction between the seams with a descending sequence (Akinkugbe 2004; Mark 2007). However, when the interburden thickness is thin, the superimposed effects increase in magnitude, which will inevitably jeopardize mine safety since the overburden becomes unstable.

When the thickness of the interburden layers exceeds a critical value, the superimposed effects can be neglected when mining in a descending sequence (Ma et al. 2009). Sui et al. (2015a) carried out a numerical simulation, scalemodel tests, and a quantitative study on the superimposed effects of overburden failure when mining close coal seams. Their study provided a critical value of the ratio of the interburden thickness against the cutting height of the lower seam for mining in a descending sequence. Fan and Zhang (2015), though, found that mining in a descending sequence damages the overburden of the lower seam when the upper coal seam is mined. This causes difficulties to the formation of a bond-beam structure on the roof of the lower coal seam, thus resulting in a more roof damage. When excavation is carried out in descending sequence, the stress relief area is distributed around the mined-out area in the shape of an annulus (Xu et al. 2014). In some geological environments, excavation in a descending sequence will increase the roadway excavation workload and required maintenance, thereby adding to the cost of mining.

Even though a descending sequence is more common, it is not a universal model for every coal mine. Excavation in an ascending sequence can reduce water and sand inrush events, gas outbursts, and rock bursts (Jin et al. 2016; Liang et al. 2013; Liu et al. 2016). Also, when the roof of the upper seam is strong or the coal is difficult to mine, an ascending sequence can be used to reduce or even eliminate the periodic pressure surge of the structure and rock bursts. When the upper seam contains aquifers with a large amount of water or if water may leak through the roof, then excavation in an ascending sequence can be used to dewater the aquifers. Furthermore, when there is a substantial volume of accumulated gas in the upper seam, the lower seam can be regarded as a protective layer, and mined first to release the gas.

However, when excavation is carried out in an ascending sequence, the roof of the seam may collapse since the lower coal seam has been completely removed, which may affect mining of the upper seam. This mainly depends on how the lower coal seam is affected by the exploitation, the location of the upper coal seam, and the geological conditions and lithology of the interburden. Feng et al. (2008) provided the basic conditions for mining in an ascending sequence: (1) when the overburden is moderately hard, the upper seam should be located above the key strata (the layer that is closest to the lower stope without the development of step-like fractures) in order to avoid damaging the floor; and (2) when the surrounding strata are relatively soft, the upper seam should be positioned inside the water-conducting fractured zone (WCFZ) of the lower stope and subsidence stabilization should precede mining. The distribution of the water-conducting fractures and the feasibility of mining in an ascending sequence have been well studied, providing a reliable basis for mining coal seams in close proximity in an ascending sequence (Jiang et al. 2012; Wang et al. 2015).

Mining under the sea or large water bodies, such as lakes, rivers, or reservoirs, adds additional risk (Alvarez et al. 2016; Loveday et al. 1983; Rubio 1986; Singh and Singh 1985; Zhang et al. 2013), as mining-induced stress and fracturing of the overburden become potentially problematic. Once fractures develop through the aquifuges and connect a water body, flooding accidents can occur (Meng et al. 2016; Singh et al. 2013). Mining a single coal seam in the Beizao coal mine under the sea was investigated for heights of overburden failure, thus providing a practical basis for decision making (Sui and Xu 2013; Wang et al. 2013; Xu and Sui 2013).

Overburden failure and deformation that occurs when mining coal seams in close proximity is important for assessing mine safety and preventing water inrush. In this paper, we will focus on the differences in the heights of overburden failure and how the progression of mining in ascending or descending sequences affects safety, using two case studies. The first involves predicting the height of the overburden failure when mining coal resources under the sea at the Beizao mine, which is mining in an ascending sequence. The second is the Cuizhuang mine, in which excavation is proceeding in a descending sequence. The two situations were compared using scale model tests, and the stress distribution, ground movement, and overburden failure heights were also compared using numerical simulations for both excavations with different interburden thicknesses. The interaction of overburden failure between the two seams was also investigated.

\section{Study Area}

\section{The Beizao Coal Mine}

The Beizao mine is located in the northwest part of the Huangxian coal field in Shandong, with an area of 
$29.63 \mathrm{~km}^{2}$. It has already produced about 11.89 million tons of coal reserve. There are three productive coal seams (Seams No. 1, 2, and 4), but this paper mainly discusses Seam No. 1 (the upper seam) and Seam No. 2 (the lower seam) in Panel H1 105 (Figs. 1, 2). Both seams have an average thickness of about $4 \mathrm{~m}$, and the latter has already been mined out. The study site is located under the sea, above which the water depth is between 9.5 and $11.5 \mathrm{~m}$. It stretches across a wide anticline. The coal measure has a gentle slope, with an average dip angle of $6^{\circ}$.

The Beizao mine bedrock is covered with unconsolidated Neogene strata with an average thickness of $84.3 \mathrm{~m}$. The gently undulating bedrock has an average thickness of $95 \mathrm{~m}$ and contains two types of lithology, over $80 \%$ of which is fragile claystone. The bedrock strata have a certain plasticity and amount of expansion, and are moderately soft. The aquifers in this area, from top to bottom comprise: a Quaternary gravel aquifer with a specific capacity between $0.1186 \mathrm{~L} / \mathrm{s} \cdot \mathrm{m}$ and $3.713 \mathrm{~L} / \mathrm{s} \cdot \mathrm{m}$; a calcareous mudstone and marlite aquifer, mudstone intercalated with marl aquifer, and the floor sandstone aquifer of Seam No. 2, with a specific capacity of $0.04 \mathrm{~L} / \mathrm{s} \cdot \mathrm{m}$. There is a clay layer at the bottom of the unconsolidated layers, which prevents water inrush from the aquifers in the unconsolidated Neogene layers. The thickness of the mudstone interburden layers between the two coal seams is $18 \mathrm{~m}$. The water-resistant bedrock strata contain mudstone, claystone, and calcareous mudstone, which are also fragile and expand easily. The Neogene system is relatively stable, and there are many aquifuges, with clay layers, including one at the bottom of the Neogene system. These clay layers isolate the coal-bearing strata from the seawater, which is probably hydraulically connected with the upper Neogene aquifer. Therefore, as long as the fractures in the overburden do not constitute a water path to the Neogene aquifers, seawater cannot infiltrate into the underground stope.

\section{The Cuizhuang Coal Mine}

The Cuizhuang mine is located in Weishan County, Shandong, China, with an area of $11.9 \mathrm{~km}^{2} .66 \%$ of its total coal resources are deposited under Weishan Lake (Supplemental Figs. 2 and 3). There are two productive coal seams (the upper seam of Seam No. 3, and the lower seam of Seam No. 3 ). The thickness of the upper and lower seams of Seam No. 3 ranges from 0 to $6.57 \mathrm{~m}$ and $0-5.17 \mathrm{~m}$, respectively. The average water depth above the mine is between 1.5 and $3 \mathrm{~m}$, and the maximum reservoir volume is 4.73 billion $\mathrm{m}^{3}$. The geological structure of the mine is generally a monocline.

The stratigraphic sequence represents the Ordovician, Carboniferous, Permian, Jurassic, and Neogene geological periods. The unconsolidated Neogene layers have an average thickness of $77.56 \mathrm{~m}$, and is thickest in the southwest and thins towards the northeast. The overburden thickness ranges from $36.4 \mathrm{~m}$ to more than $200 \mathrm{~m}$, and the strength of the overburden is weak to moderate. The interburden layer between the two coal seams is $7 \mathrm{~m}$ thick and is mainly sandy mudstone. The floor of the lower seam contains mudstone
Fig. 1 Tectonic structure in the Beizao coal mine

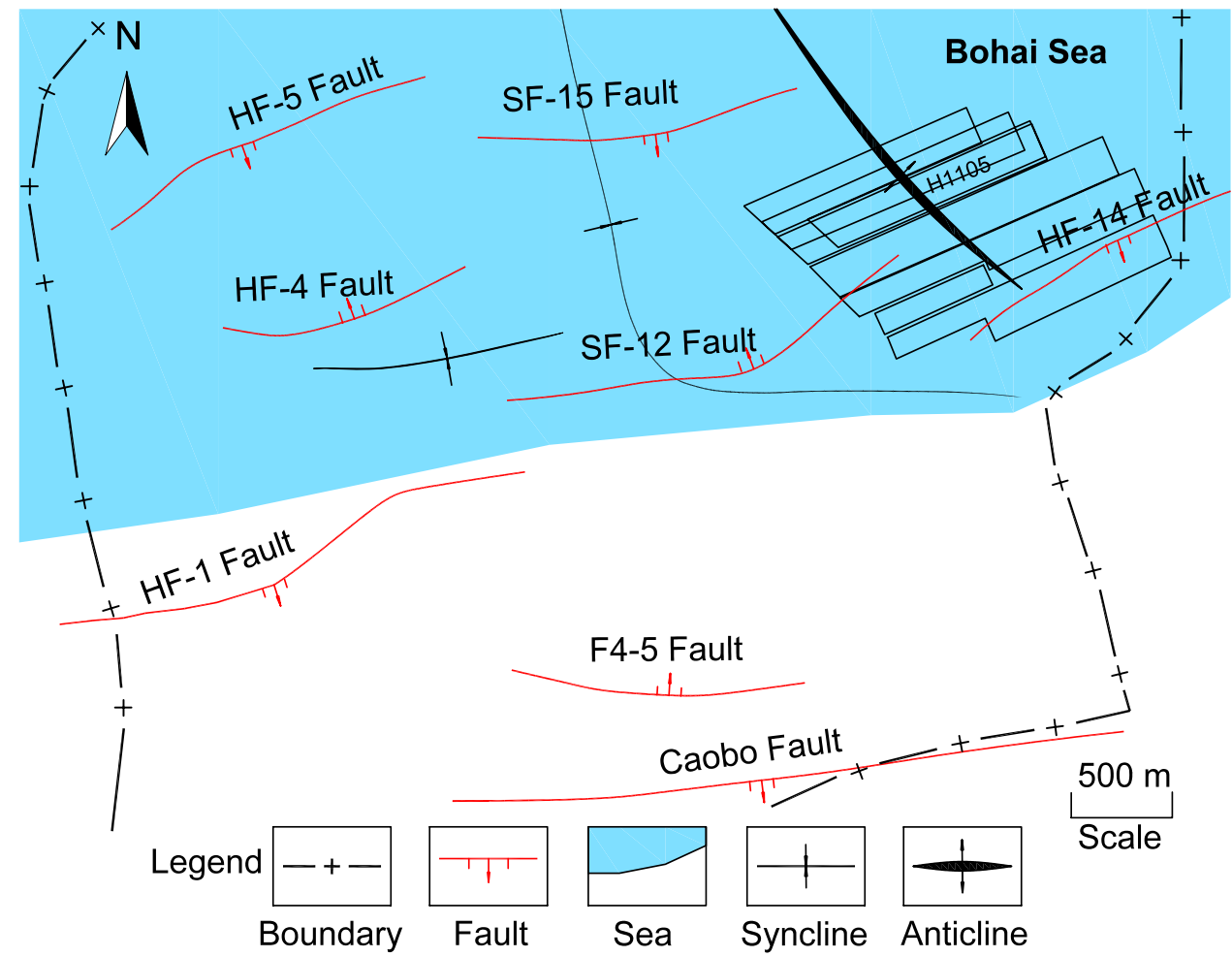




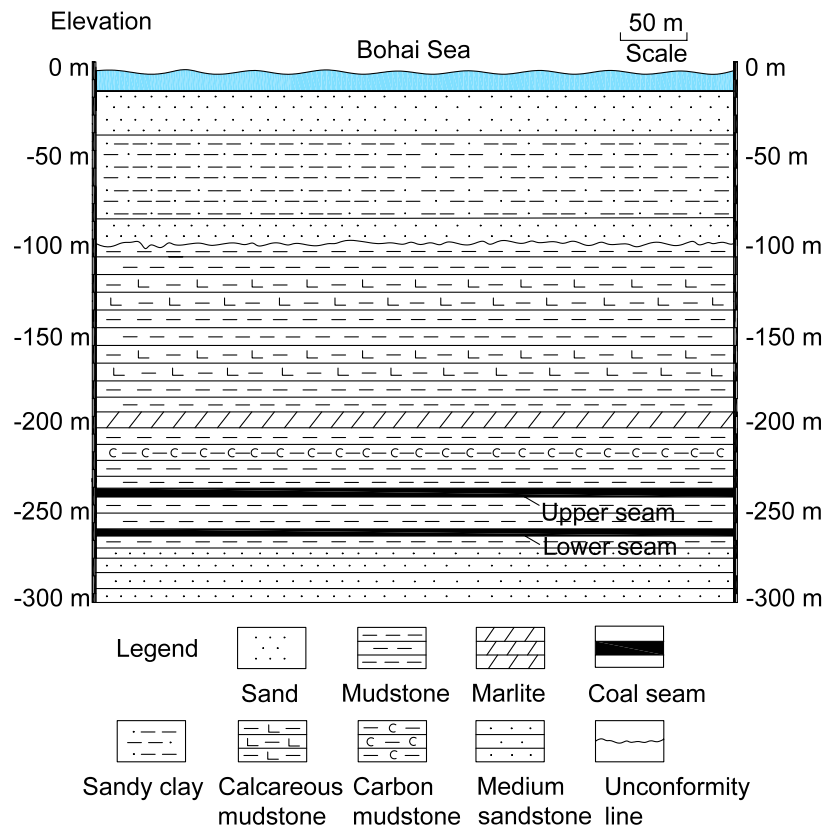

Fig. 2 Stratigraphic section of a panel along the strike in the Beizao coal mine

and fine sandstone, which is horizontally bedded with vertical fissures. Water inrush and seepage from the aquifers in the unconsolidated Neogene layers are probably inhibited by a $5.31-23.18 \mathrm{~m}$ thick clay layer at the bottom of the Neogene strata. Confined sandstone aquifers in fissured conglomerates in the Jurassic layers have a specific capacity of $0.4 \mathrm{~L} / \mathrm{s} \cdot \mathrm{m}$, but the Permian sandstone aquifers pose the greatest threat, as they are located above the two coal seams and have a specific capacity of $0-0.7 \mathrm{~L} / \mathrm{s} \cdot \mathrm{m}$. Water normally flows into the mine at a constant $40 \mathrm{~m}^{3} / \mathrm{h}$ from these aquifers.

\section{Method}

\section{In-situ Measurement}

In-situ measurements from the Liangjia coal mine are used here as their engineering geological and hydrological conditions are quite similar to those of the Beizao mine. Successful mining of thin and thick seams, slice mining of thick seams, and mining of close seams have been carried out in both of these mines. In each, there have been observations of overburden failure that occurred in the panels. In Panel 1111 of the Liangjia mine, the superimposed effects and heights of the overburden failure were measured in-situ for mining the upper seam after the lower seam had already been mined out. These in-situ measurements provide a reliable means to predict the heights of the overburden failure for mining in an ascending sequence in the Beizao mine.
The upper and lower seams of Panel 3301 of the Cuizhuang mine were selected for height of overburden failure measurements. Instead of using hydrological observations during surface drilling, field observations were carried out by drilling upward boreholes in different directions. Then water was injected and drained to find strata fractures, and the amount of water loss was compared to identify the heights of overburden failure. However, drilling should be avoided in the caving zone. Instead, drilling should be carried out in the WCFZ, to reach a certain height above the fractured zone. Since an existing panel in the Liangjia mine, and the studied panels of the Beizao and Cuizhuang mines are geologically similar, the heights of the overburden failure can be easily predicted. Comparing their differences and similarities allows an analysis by analogy that can be optimally applied for real-life mine safety.

\section{Empirical Calculations}

In the longwall mining of gently inclined coal seams, there are three representative zones of overburden failure. From bottom to top, they are: the caving, fractured, and bending (continuous deformation) zones. In the caving zone, there are connective gaps that allow water and sediment inrushes into underground channels. In the fractured zone, there are primarily two types of fractures; vertical and bed separation (fractures along the layers). When these two types of fractures connect, the permeability of the layers increases. The caving and fractured zones constitute the WCFZ and may also constitute a path for water to infiltrate from aquifers into the working panels. In the bending zone, the separation gaps are generally small, although bed separation fractures can also develop in the lower part of the bending zone. These bed separation fractures though are only partially filled with water and are not linked to the water-conducting fractures. In general, the bending zone acts as an aquifuge; therefore, as long as the WCFZ does not reach the aquifer, mining under water bodies will not induce water or sand inrush into the working panels (Sui et al. 2015a).

According to the State Administration of Work Safety et al. (2017), when the height of the caving zone of the lower seam $\left(H_{\mathrm{m}}\right)$ is less than the thickness of the interburden layers $(h)$, the heights of the WCFZ of the coal seams are calculated separately and the higher one is chosen. The heights are calculated by the formulae in Table 1 . When the caving zone propagates into the upper coal seam or stope $\left(H_{\mathrm{m}}>h\right)$, the heights of the WCFZ are calculated from an equivalent mined height $M_{\mathrm{S}}$ (by using Eq. 1) and the mined height of the upper seam, $M_{\text {upper }}$, then the higher one is chosen.

$$
M_{\mathrm{s}}=M_{\text {lower }}+\left(M_{\text {upper }}-\frac{h}{y_{\text {lower }}}\right) \text {, }
$$


where $M_{\text {lower }}$ is the mined height of the lower seam; $M_{\text {upper }}$ is the mined height of the upper seam; $h$ is the thickness of the interburden layers; $y_{\text {lower }}$ is the ratio of the height of the caving zone of the lower seam to the mined height of the lower seam.

\section{Scale Model Testing}

In the Beizao mine case study, a scale model was built along strike with the following ratios: geometry $-1 / 200$, time constant $-1: \sqrt{200}$, bulk weight -0.75 , and strength $-3 / 800$. The model size was $300 \mathrm{~cm} \times 30 \mathrm{~cm} \times 140 \mathrm{~cm}$ (length $\times$ width $\times$ height). Two coal pillars of $60 \mathrm{~m}$ in length were left at each end to reduce boundary effects. The mined length was $480 \mathrm{~m}$ (Supplemental Fig. 4). Since the overburden rock is moderately weak with a compressive strength of 20-30 MPa, sand, calcium carbonate, gypsum, and mica were chosen as similar materials. The parameters of the physical model and engineering geology strata are listed in Supplemental Table 1. A vertical load was applied on top of the model to simulate gravitational stress distribution, since the partially unconsolidated layers were not built into the model. The lower seam was excavated first by longwall caving, advancing $5 \mathrm{~cm}$ (equal to $10 \mathrm{~m}$ in the prototype) for each step; the interval between each step was $4 \mathrm{~h}$. After the rock strata stabilized, the upper seam was also excavated by longwall caving, advancing $5 \mathrm{~cm}$ for every step at an interval of $4 \mathrm{~h}$.

A scale model along strike was also established for the Cuizhuang mine, with the following ratios: geometry $-1 / 100$, bulk weight $-1 / 1.7$, and strength $-1 / 100$, as found in Sui et al. (2015a). The model size was $300 \mathrm{~cm} \times 30 \mathrm{~cm} \times 130 \mathrm{~cm}$ (length $\times$ width $\times$ height). Coal pillars of 60 and $82.5 \mathrm{~m}$ were left at each end to reduce boundary effects. The mined length was $110 \mathrm{~m}$ (see Supplemental Fig. 5). The mined height of the upper and lower seams was 6.0 and $4.3 \mathrm{~m}$, respectively. The thickness of the interburden layer was $10.6 \mathrm{~m}$. Sand, barite, gypsum, mica, etc. were combined for use as the modeled materials. The material parameters are listed in Supplemental Table 2. The excavation was carried out in the same way as that of the Beizao mine.

\section{Numerical Simulation}

The Universal Distinct Element Code (UDEC) was used in this study to simulate the excavation process using the engineering geological and mining conditions of the Beizao mine area. The model was set at an area of $800 \mathrm{~m} \times 280 \mathrm{~m}$, and the length of the working panel was $600 \mathrm{~m}$, with coal pillars $100 \mathrm{~m}$ in length at the edge of each working panel (Fig. 3). To enhance the accuracy of the numerical test, the size and stratum settings of the numerical model were the same as that of the actual panel. The displacements were fixed on the bottom and on both side boundaries. The top of the model was set as a free displacement boundary. Based on previous experience in both mines, the height of the WCFZ cannot exceed $60 \mathrm{~m}$ due to the mining of two seams. Therefore, a $100 \mathrm{~m}$ wide boundary was left at both sides of the panel to mitigate the boundary effect.

One of the models simulated the scale model. Since the interburden thickness is $18 \mathrm{~m}$, there was no obvious interaction between the two seams. This model, with no apparent interaction between the seams, was also used to verify the accuracy of the results of the numerical simulation. The heights of the WCFZs of the calculated, simulated, and scaled tests were 50,55.8, and $55 \mathrm{~m}$, respectively; the heights of the caving zone were 10.6, 18.2, and $13.0 \mathrm{~m}$, respectively (Table 2 ). The heights of overburden failure measured by these methods were in a good agreement, which also demonstrates the reliability of the numerical simulation.

To compare the differences and effectiveness of the model with both mining sequences, excavation in a descending sequence was also evaluated. Then, another model was built in which there would be interactions between the seams, using the same geological conditions except that the interburden thickness was set at $10 \mathrm{~m}$, since the caving zone develops over $10 \mathrm{~m}$ when the mined height is $4 \mathrm{~m}$, based on
Table 1 Formulae for calculating heights of caving and water-conducting fractured zones

\begin{tabular}{|c|c|c|c|}
\hline \multirow[t]{2}{*}{ UCS of rock (MPa) } & \multirow{2}{*}{$\begin{array}{l}H_{\mathrm{c}} \\
\text { Formula }\end{array}$} & \multicolumn{2}{|l|}{$H_{\mathrm{f}}$} \\
\hline & & Formula 1 & Formula 2 \\
\hline Hard (40-80) & $H_{\mathrm{c}}=\frac{100 \sum M}{2.1 \sum M+16} \pm 2.5$ & $H_{\mathrm{f}}=\frac{100 \sum M}{1.2 \sum M+2.0} \pm 8.9$ & $H_{\mathrm{f}}=30.0 \sqrt{\sum M}+10.0$ \\
\hline Moderate-hard (20-40) & $H_{\mathrm{c}}=\frac{100 \sum M}{4.7 \sum M+19} \pm 2.2$ & $H_{\mathrm{f}}=\frac{100 \sum M}{1.6 \sum M+3.6} \pm 5.6$ & $H_{\mathrm{f}}=20.0 \sqrt{\sum M}+10.0$ \\
\hline Weak (10-20) & $H_{\mathrm{c}}=\frac{100 \sum M}{6.2 \sum M+32} \pm 1.5$ & $H_{\mathrm{f}}=\frac{100 \sum M}{3.1 \sum M+5.0} \pm 4.0$ & $H_{\mathrm{f}}=10.0 \sqrt{\sum M}+5.0$ \\
\hline Extra-weak $(<10)$ & $H_{\mathrm{c}}=\frac{100 \sum M}{7.0 \sum M+63} \pm 1.2$ & $H_{\mathrm{f}}=\frac{100 \sum M}{5.0 \sum M+8.0} \pm 3.0$ & - \\
\hline
\end{tabular}

$\sum M$ cumulative thickness of coal seams 


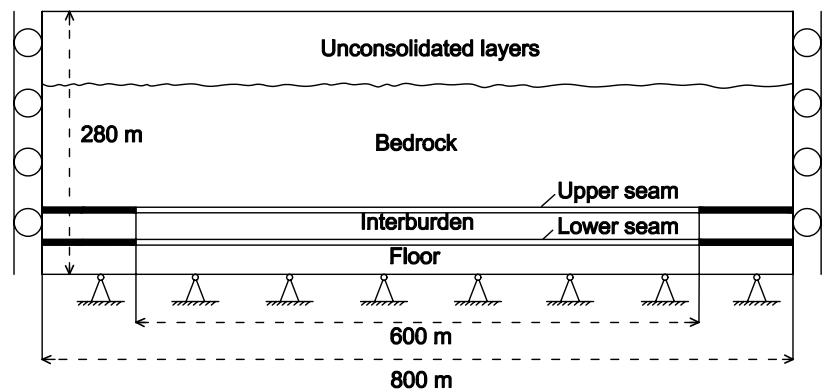

Fig. 3 A conceptual model for numerical simulation test

the empirical formulae (Table 1). Ascending and descending sequences were both assessed with this interacting model to: (1) verify the possibility of mining the upper seam above a lower stope in an ascending sequence; (2) compare the differences in overburden failure for the two mining sequences, as they progress; and (3) investigate the effects of the interactions on overburden strata disturbance for both ascending and descending mining sequences.

According to Sui et al. (2015b), the range of the vertical displacement values in the numerical simulation is approximately equal to the mined heights. Combining this with where the tensile failure that occurs in the plastic zone, and this is the approximate height of the caving zone. The height of the WCFZ is determined by the height of the developing open and split fractures, which are also in agreement. Therefore, in this study, the heights of the caving and WCFZs were evaluated by using the distribution of the vertical displacement, tensile failure, and the propagation of open and split fractures.

\section{Results}

Based on the in-situ measurements, empirical calculations, and scale and numerical simulation models, the heights of overburden failure due to excavation in ascending and descending sequences are provided in Tables 2 and 3, respectively. The results can also serve as a reference for other studies that intend to use numerical simulation to compare overburden failure and the surrounding stresses for different mining sequences and interburden thicknesses.

\section{Propagation of Overburden Failure with Excavation in Ascending and Descending Sequences: Scale Modeling}

\section{Model for the Beizao Coal Mine}

The WCFZ developed during excavation of the lower coal seam, but the fractures stopped propagating after mining 
advanced after $260 \mathrm{~m}$. As mining progressed, the immediate roof first fell within $70 \mathrm{~m}$ in horizontal as the mining advanced to $80 \mathrm{~m}$. Then, the caving and WCFZs quickly increased in size. After mining $210 \mathrm{~m}$, there were no further increases in the height of the caving zone, although the WCFZ continued to increase. Finally, the rate of increase in the height of the WCFZ slowed down until there were no further increases. During the mining process, cracks in the overburden layers gradually developed, became compacted, and then closed, which was an ongoing cycle. The maximum heights of the caving and WCFZs were 12 and $41 \mathrm{~m}$, respectively, which formed a saddle-shaped distribution (Fig. 4a). This is because that the pillars on both sides had a highly developed supporting strength, while in the middle, the collapsed rocks were compacted, so that relatively few fractures developed. The integrity of the interburden layers was good but the upper seam was inside the WCFZ.

The floor of the upper seam was disturbed by mining of the lower seam, since it was $23 \mathrm{~m}$ above the upper roof, within the range of the WCFZ of the lower seam. Bed separation fractures developed; most were compacted under load transfer from the upper seam and there was obvious stratification of the strata. When the coal from the upper seam was removed, the overburden near the opening of the cut section deformed slightly due to the development of some vertical micro-fractures. When the width of the mined section advanced to $70 \mathrm{~m}$, the upper roof collapsed, and vertical fractures developed upwards on both sides. When the recovery advanced to between 160 and $230 \mathrm{~m}$, the overburden fractures closed due to compaction of the collapsed material in the caving zone, limiting further development of the WCFZ. The maximum height of the caving and WCFZs was 13 and $55 \mathrm{~m}$, respectively, and both showed a saddle shape (Fig. 4b). The WCFZ of the upper seam was $14 \mathrm{~m}$ greater in height than that of the lower seam, but did not reach any aquifers.

\section{Model of the Cuizhuang Coal Mine}

In the Cuizhuang mine model, the immediate roof collapsed when mining advanced to $24 \mathrm{~m}$. Then the roof layers cracked, fractures propagated upwards, and collapsed rock filled the mined out area. The maximum height of the WCFZ was $48.0 \mathrm{~m}$, and that of the caving zone was $17.6 \mathrm{~m}$ (Fig. 5a). The WCFZ developed a pattern that was ladder-like in shape. Fractures only developed vertically, mostly along the open cut, and their width and extended length were negligible; at any rate, they had little influence on the lower seam and the interburden.

Mining the lower seam obviously influenced the overburden fractures. The interburden layers collapsed when mining advanced to $44 \mathrm{~m}$. Fractures emerged in the upper part of the overburden and propagated to the WCFZ. The caving zone of the lower seam approached the upper stope as mining advanced to $55 \mathrm{~m}$. The maximum height of the caving and WCFZs was 27.0 and $69.0 \mathrm{~m}$, respectively, extending above the upper stope after the two seams were mined. The WCFZ again had a ladder-like shaped pattern, and numerous fractures developed on both sides, especially at the open cut (Fig. 5b). The total height of the WCFZ was $21 \mathrm{~m}$ more than when only the upper seam was mined, and almost reached the bottom clay layer.

\section{Stress and Strain, Displacement, and Overburden Failure from Numerical Simulation}

Numerical simulations were carried out to compare the characteristics of the overburden movement and the stresses of ascending and descending mining sequences. The different sequences were simulated under the same geological conditions, but with two interburden layer thicknesses: $18 \mathrm{~m}$, which was the thickness used in the model with no apparent interaction between the two seams, and $10 \mathrm{~m}$, which is close enough to interact, according to Table 1.

\section{Stress and Strain}

Figure $6 \mathrm{~b}$ and Supplemental Figs. $6 \mathrm{~b}, 7 \mathrm{~b}$, and $8 \mathrm{~b}$ show the principal stress distribution of the ascending and descending sequences, for the model with no apparent interaction between the seams. As excavation in ascending sequence advanced, the stress was concentrated above the lower coal pillars and in the middle of the mined-out area. Serious

Table 3 Comparison of overburden failure by using UDEC for excavation in ascending and descending sequences with different interburden thicknesses

\begin{tabular}{llllllll}
\hline Mining sequence & $\begin{array}{l}\text { Thickness of inter- } \\
\text { burden }(\mathrm{m})\end{array}$ & $H_{\mathrm{c} \text {-upper }}(\mathrm{m})$ & $H_{\mathrm{f}}(\mathrm{m})$ & $\begin{array}{l}\text { Major principal } \\
\text { stress (MPa) }\end{array}$ & $\begin{array}{l}\text { Horizontal } \\
\text { stress (MPa) }\end{array}$ & $\begin{array}{l}\text { Vertical stress } \\
(\mathrm{MPa})\end{array}$ & $\begin{array}{l}\text { Surface } \\
\text { subsidence } \\
(\mathrm{m})\end{array}$ \\
\hline Ascending & 18.0 & 18.2 & 55.8 & 18.0 & 14.0 & 18.0 & 3.375 \\
Descending & & - & 50.8 & 16.0 & 10.0 & 16.0 \\
Ascending & 10.0 & 23.4 & 59.5 & 16.0 & 16.0 & 16.0 & 3.636 \\
Descending & & - & 64.5 & 25.0 & 14.0 & 25.0 & 3.119 \\
\hline
\end{tabular}


Fig. 4 Scale model of excavation in an ascending sequencethe Beizao coal mine

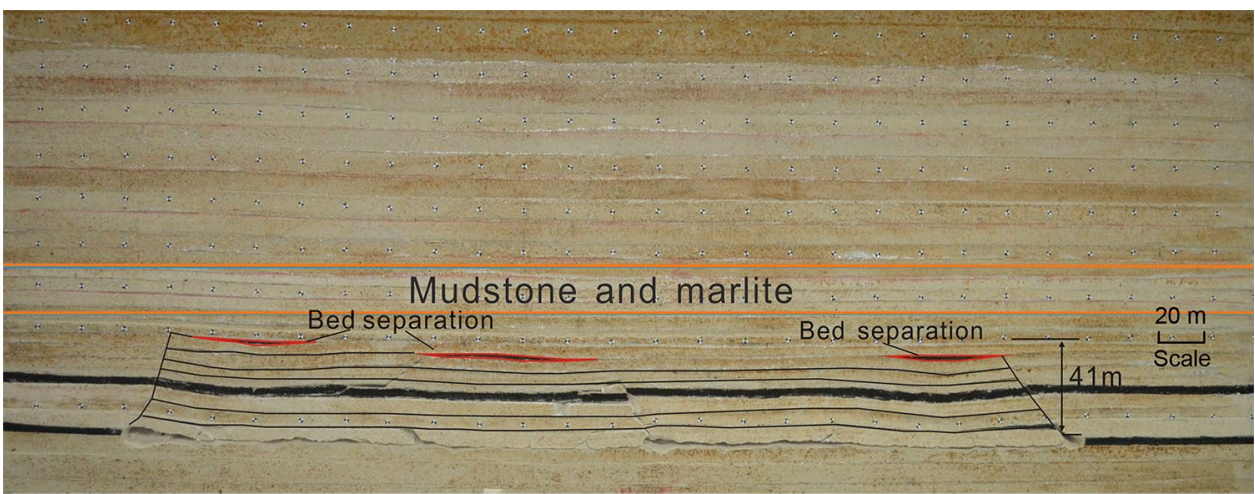

(a) Mining the lower seam

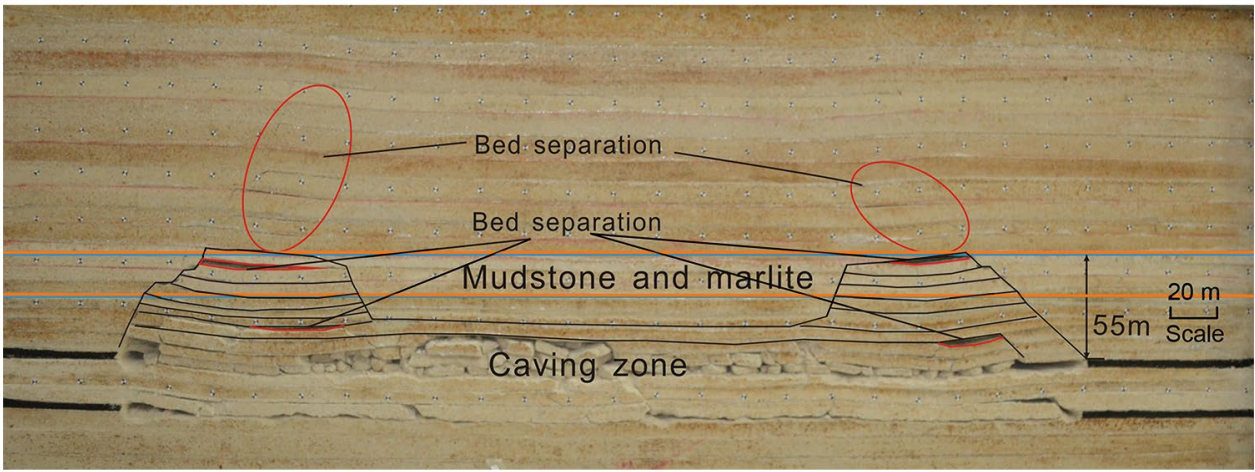

(b) Mining two seams shear failure occurred above the diagonal of the pillars of the lower seam after that seam was mined. The contour space in the maximum principal stress distribution was small, which means that the stress was released, resulting in tensile shear damage and broken rock layers. After both seams were mined in an ascending sequence, the concentrated stress expanded to the pillars of the upper seam. An area of obvious concentrated stress emerged above the middle of the mined-out area of the upper seam. However, the most stress on both sides was still found in the lower stope, and stress developed upwards.

On the other hand, with a descending sequence, the stress was concentrated in the upper stope, and developed downwards. The maximum values of the major principal stresses of mining one or two seams in an ascending sequence were both $18 \mathrm{MPa}$, while those of a descending sequence were 12 and $16 \mathrm{MPa}$, respectively. Moreover, the maximum values of the horizontal and vertical stresses of the two seams were 14 and $18 \mathrm{MPa}$, respectively, with an ascending sequence, and 10 and $16 \mathrm{MPa}$, respectively, with a descending sequence.

By modeling the seam interactions as mining advanced with both sequences, we found that the developing trend and distribution of the principal stresses were similar to those in the model with no apparent interaction (see Fig. 7b and Supplemental Figs. 9b, 10b and 11b). With an ascending sequence, the maximum major principal stress while mining one and two seams was $16 \mathrm{MPa}$, while with a descending sequence, the maximum major principal stress was 12 and $25 \mathrm{MPa}$, respectively. The maximum value of the horizontal and vertical stresses while mining the two seams in an ascending sequence was also $16 \mathrm{MPa}$ for both, while that of the descending sequence was 14 and $25 \mathrm{MPa}$, respectively.

\section{Displacement}

As mining advanced in the model with no apparent interaction between the two seams, the subsidence of the overburden layers gradually increased, and the extent of the influence on the rock layers also increased. After mining out the lower seam in an ascending sequence, the area within $16.8 \mathrm{~m}$ above the mined-out area had the most subsidence. There were three maximum values of subsidence above the stope after mining the lower seam, which maintained the same shape when the upper seam was mined (Fig. 6a and Supplemental Fig. 7a). The entire subsidence area was shaped like a trapezoid. When the upper seam was mined in a descending sequence, the subsidence area was shaped like a saddle, with an obvious maximum value. The subsidence maintained this saddle-like shape after the lower seam was mined. The magnitude of the surface subsidence in the ascending sequence $(3.375 \mathrm{~m})$ was less than that for mining in a descending sequence $(3.636 \mathrm{~m})$. Viewed as a whole, with a descending 
Fig. 5 Scale model of excavation in a descending sequencethe Cuizhuang coal mine

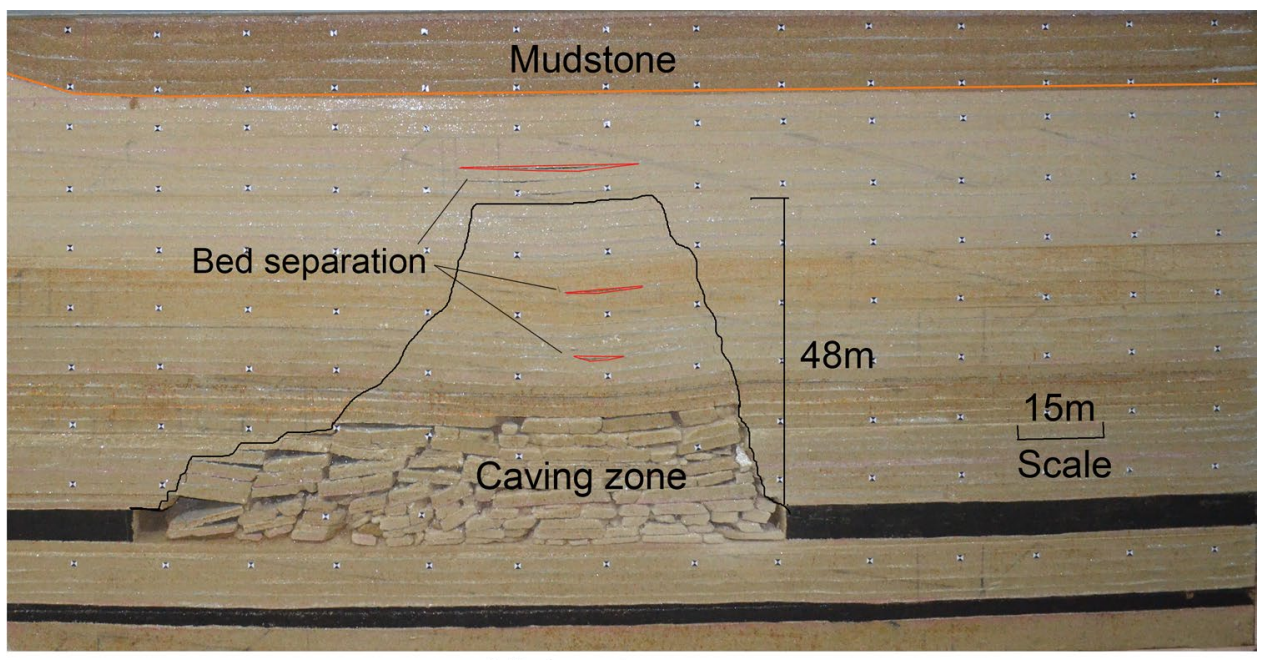

(a) Mining the upper seam

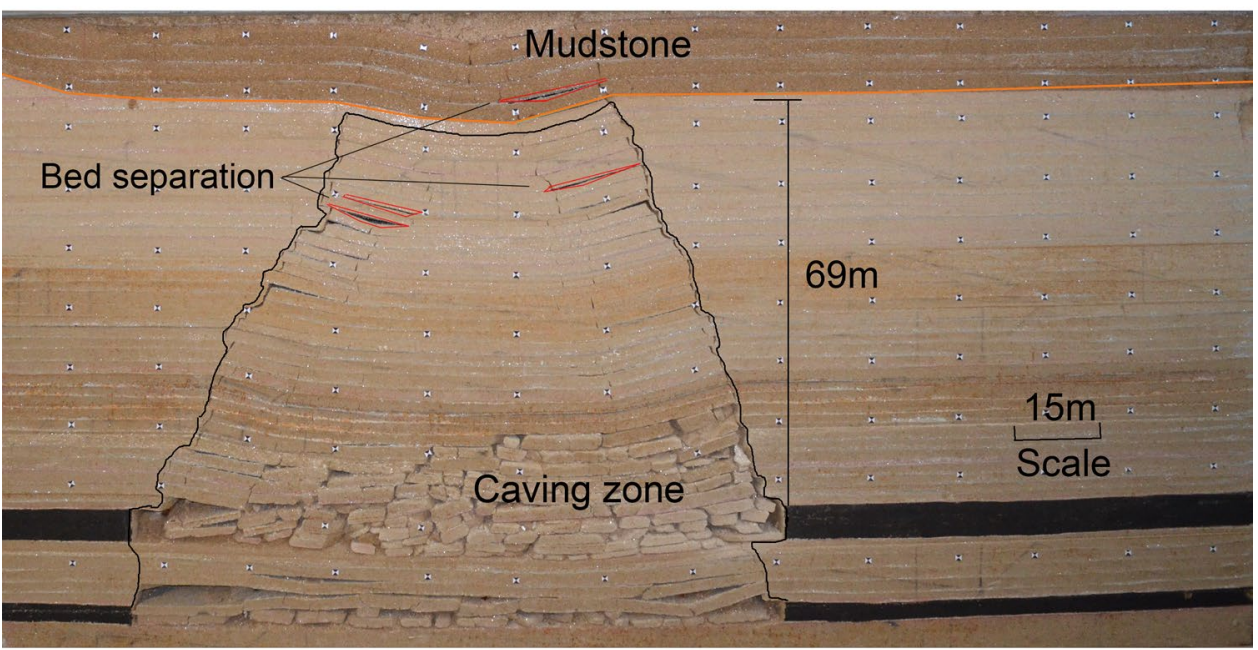

(b) Mining two seams sequence, the magnitude of the subsidence in the overburden layers was greater than with an ascending sequence (Fig. 6a and Supplemental Fig. 6a). Moreover, the caving zone of the lower seam at the open cut propagates into the upper stope with a descending sequence (Supplemental Fig. 6a), but not with mining in an ascending sequence.

The trends found while modeling the interaction between the seams demonstrate some similarities with those in the model with no apparent interaction (Fig. 7a and Supplemental Figs. 9a, 10a, and 11a). As the thickness of the interburden layers was less than the height of the caving zone when mining the lower seam, there was interaction between the seams with both sequences. Collapses in the caving zone substantially affected the floor of the upper seam or the upper stope, thus causing greater subsidence in the upper stope (see vertical displacement of 3-4 $\mathrm{m}$ in Fig. 7a and Supplemental Fig. 9a). Specifically, the collapse occurred over a larger area when mining in an ascending sequence. Also, with an ascending sequence, the magnitude of the subsidence of all of the areas that surrounded the overburden was greater than that with a descending sequence. The maximum surface subsidence with ascending and descending sequences were 3.352 and $3.119 \mathrm{~m}$, respectively.

\section{Development of Overburden Failure}

After modeling the excavation of the two seams in a descending sequence under the assumption that there would be no apparent interaction, substantial bed separation fractures developed above the pillars. However, there were fewer vertical fractures that propagated to the bed separation fractures or aquifers. In comparison, excavation of the lower seam in an ascending sequence led to the formation of stepped fractures in the roof strata of the upper seam, which would affect the safety of mining the upper seam. During excavation in an ascending sequence, the roof fractures were more developed and concentrated. This was true not only for 


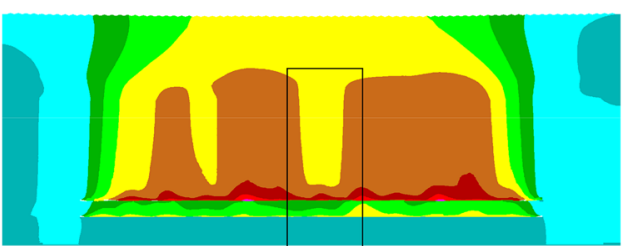

(a)

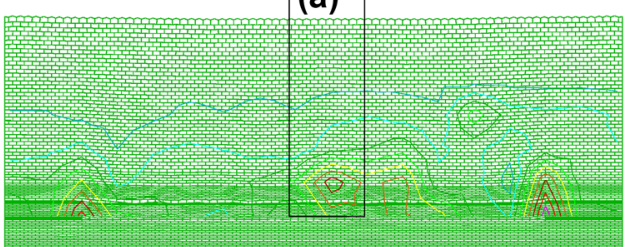

(b)

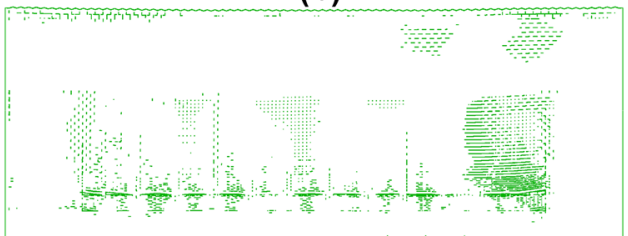

(c)
$Y$ displacement contours -7.000E t00 to $0.000 \mathrm{E}+00$ D. O00E +00

$-7.000 \mathrm{E}+00$
$-6.000 \mathrm{E}+00$ $-6.000 E+00$
$-5.000 E+00$
$-4.000 E+00$ $-4.000 E+00$
$-3.000 E+00$ $-3.000 E++00$
$-2.000 E+00$ $-1.000 E+00$ $0.000 E+00$ block plot major principal stress cont contour interval $=2.000 \mathrm{E}+0$ $1.800 E+07$ to $-2.000 E+06$ $-1.800 \mathrm{E}+07$ $-1.600 E+07$ $-1.400 E+07$ $-8.000 \mathrm{E}+06$ $-8.000 E+06$
$-6.000 E+06$
$-4.000 E+06$ $-2.000 \mathrm{E}+06$

boundary plot joints with $\mathrm{FN}$ or $\mathrm{SN}=0.0$ joints now at shear limit Ascending

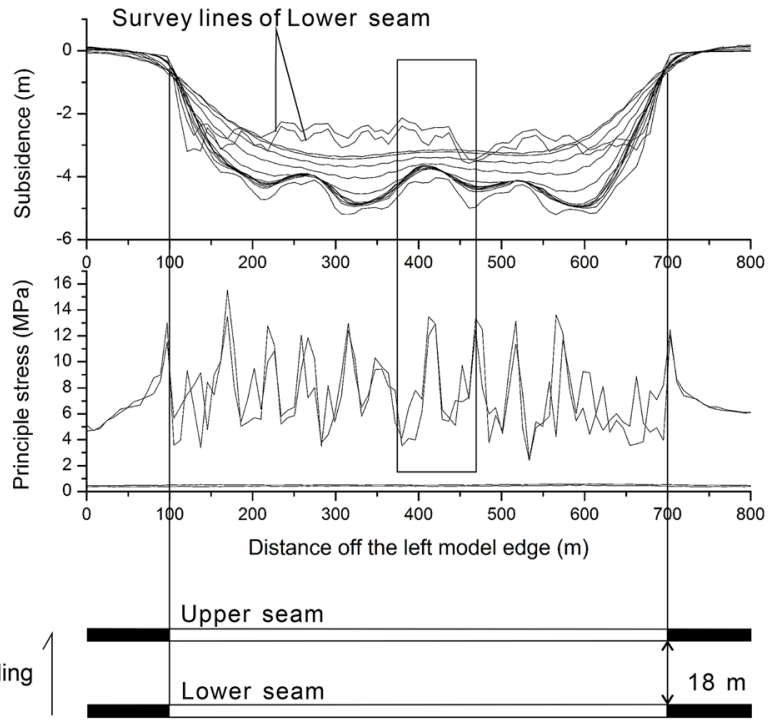

(d)

Fig. 6 Modeling of excavation of two seams in an ascending sequence with no apparent interaction. a Distribution of vertical displacement. b Distribution of major principal stress. c Development of open fractures and slip zones. d Subsidences of overburden failure above the lower seam at every $16.5 \mathrm{~m}$ and the principal stress distribution of the roof of two seams

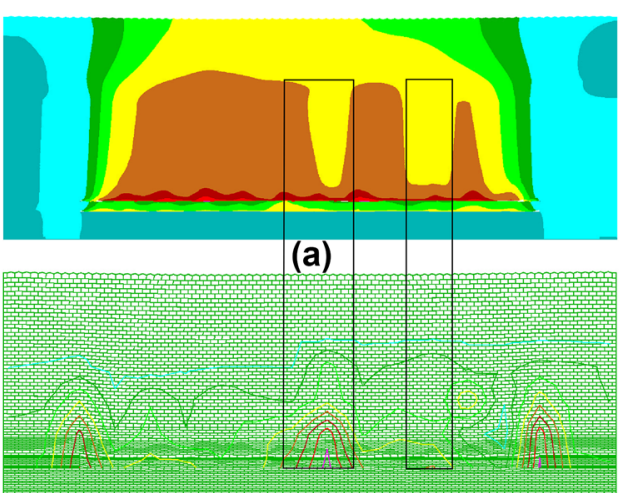

(b)

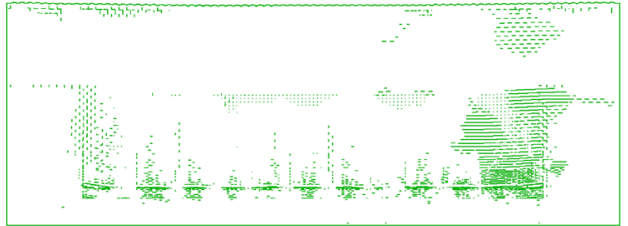

(c)
$Y$ displacement contours $-7.000 \mathrm{E}+00$ to $0.0000+00$

$-7.000 \mathrm{E}+00$ $-6.000 \mathrm{E}+00$
$-5.000 \mathrm{E}+00$ $-5.000 E+00$
$-4.000 E+00$ $-3.000 \mathrm{E}+00$ $-2.000 \mathrm{E}+00$ $-1.000 E+00$
$0.000 E+00$ lock plot major principal stress cont contour interval $=2.000 \mathrm{E}+06$ th $-2.000 \mathrm{E}+06$ $-1.600 \mathrm{E}+07$
$-1.400 \mathrm{E}+07$
$-1.200 \mathrm{E}+07$ $-1.400 E+07$
$-1.200 E+07$ $-1.200 \mathrm{E}+07$
$-1.000 \mathrm{E}+07$ $-6.000 \mathrm{E}+06$ $-4.000 \mathrm{E}+06$ $-2.000 \mathrm{E}+0 \mathrm{0}$

boundary plot joints with FN or SN $=0.0$ joints now at shear limi
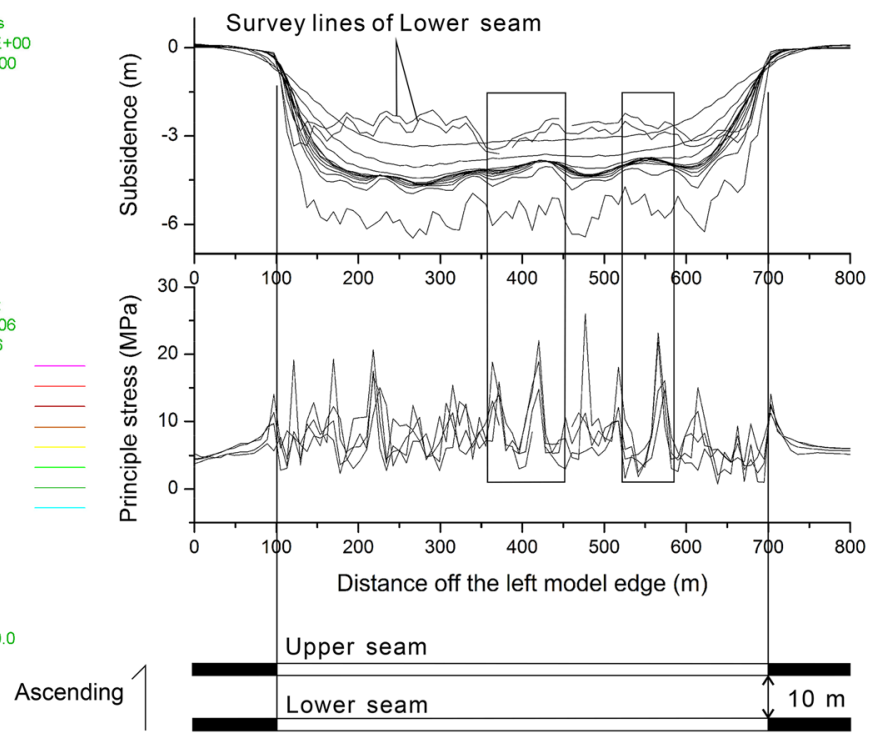

(d)
Fig. 7 Modeling of excavation of two seams in an ascending sequence with interaction between seams. a Distribution of vertical displacement. b Distribution of major principal stresses. c Develop-

the vertical and bed separation fractures that developed at the two ends of the stope (especially the stopping line), but also above the upper stope. The length of the collapsed rock mass was relatively short, and the periodic roof weighting interval of the mining in an ascending sequence was slower ment of open fractures and slip zones. d Subsidences of overburden failure above the lower seam at every $16.5 \mathrm{~m}$ and the principal stress distribution on roof of two seams

than that of a descending sequence. The interburden layers were affected by mining the upper seam, and additional compressive deformation was produced, which increased the compactness of the collapsed rock mass of the caving zone in the lower stope. When no apparent interaction was 
assumed, the fractures were squeezed, bed separation fractures were closed, overburden layers sank, the fractured zone propagated to the area of the upper seam, and the whole rock structure consisted of a half-arch shape (Fig. 6c and Supplemental Figs. 6c, 7c, and 8c). The height of the WCFZ was $55.8 \mathrm{~m}$ when mining both seams with an ascending sequence and $50.8 \mathrm{~m}$ with a descending sequence.

Open and bed separation fractures were extensively distributed in the overburden layers after mining, under the assumption of interaction between the seams. Vertical fractures developed above the stopping line, which were more developed and extended upwards as opposed to when no apparent interaction was assumed. There were more bed separation fractures with a descending sequence and the height of the WCFZ was 59.5 and $64.5 \mathrm{~m}$, respectively, when the seams were mined in ascending and descending sequences when interaction between the seams was assumed (Fig. 7c and Supplemental Figs. 9c, 10c, and 11c).

\section{Discussion}

\section{Comparison Between Mining in Ascending and Descending Sequences with No Apparent Interaction}

When two coal seams are near each other, they are usually mined in a descending sequence. This is mainly because disturbance to the roof caused by mining the upper seam can be great while damage to the floor by mining is typically minimal. However, after mining the upper seam, the supporting stress in the upper surrounding rock mass may be transferred through the coal pillars to the lower coal seam. This would produce an increased area of stress as the lower seam is mined. Therefore, when mining in a descending sequence, using a layout with lower drifts could avoid the range of effects from upper pillars, if there are any in the upper stope.

Fractures that develop from excavation in a descending sequence were concentrated at both ends of the mined-out area. However, there were fewer fractures above the minedout area than with an ascending sequence, and the same was true for bed separation fractures. With a descending sequence, the length of the collapsed rock block was relatively long, which meant that the periodic roof weighting interval was longer. As the lower seam was mined in a descending sequence, bed separation fractures developed upwards, cracking the floor of the upper stope, which caused the rock mass to collapse. This also induced a large range of vertical displacement of the overburden layers in the middle of the working panel.

Mining in a descending sequence is not suitable for mining under stopes that are filled with water, but can be otherwise used to control overburden deformation. The disturbance to the roof caused by mining the upper seam first causes water-conducting fractures to form, which can block the downwards transfer of the overburden load. However, after the upper seam is mined, the supporting stress in the upper surrounding rock mass may be transferred through the coal pillars to the lower coal seam. This produces an area of increased stress in the mined area of the lower seam.

During mining in an ascending sequence, the stress in the overburden layers first increases and then decreases. After a short period of stabilization, the stress increases and then decreases again, until equilibrium is achieved. During this process, as stress peaks and then declines, collapse and damage occurs in the overlying layers. The stress in the overburden strata is redistributed, which reduces the stress in the upper seam. During mining of the upper seam, the supporting stress of the lower stope is released, transmitted, and transferred, and then, the total value of the supporting stress decreases. The maximum principal stress while mining in a descending sequence is less than that of an ascending sequence. Also, the stress produced by an ascending sequence is more concentrated because the stress cannot be released, and the stress produced by mining each coal seam is superimposed, which also increases the boundary stress. This means that the superimposed disturbance of mining in an ascending sequence is greater than that of a descending sequence. Also, more ground subsidence occurs in an ascending sequence, which may negatively affect mining of the upper seam.

In an ascending sequence, the roof of the lower seam collapses during mining of the lower seam, causing many fractures to form in the upper seam. These fractures can connect the lower and upper seams, allowing air to flow from one seam to the other (Ma et al. 2007). Then, if the lower stope contains methane, the air flow and air pressure must be adjusted or other solutions used during mining of the upper seam to prevent gas emission and spontaneous combustion during production (Ma et al. 2009).

\section{Comparison Between Interaction and No Apparent Interaction with Ascending or Descending Mining Sequences}

According to the numerical simulations, there is more concentrated stress with an ascending sequence, if no apparent interaction between the seams is assumed (interburden thickness of $18 \mathrm{~m}$ ). But when interaction is assumed (interburden thickness of $10 \mathrm{~m}$ ), there is more concentrated stress with a descending sequence. The maximum value of the horizontal and vertical stresses decreases by 28.6 and $11.1 \%$ with a descending sequence and modeling that assumes no apparent interaction, respectively. However, when interaction was assumed, horizontal stress was reduced by $14.3 \%$, but vertical stress increased by $36 \%$ with a descending sequence. 
This is mainly because the interaction between the two seams influences stress concentration.

More fractures developed above the stope and pillars with an ascending sequence when the model assumed no apparent interaction, while more fractures developed in a descending sequence when the model assumed interaction. With no apparent interaction and an ascending sequence, the ratio of the height of the caving zone to the mined height, and that of the height of the WCFZ to the mined height were 4.55 and 13.95, respectively; for a descending sequence, fractures developed mostly above the pillars and the ratios were 4.25 and 12.7 , respectively.

If interaction is assumed, the ratios of the heights of the overburden failure to the mined height are much larger, with 14.88 and 16.13 for ascending and descending sequences. Furthermore, the interaction between the two seams leads to greater fracture development when mining in a descending sequence. The ratio is $27 \%$ greater than where there is no apparent interaction. According to Fig. 7a and Supplemental Figs. 9a, 10a, and 11a, the vertical displacements demonstrate more movement within the overburden layers (and more subsidence) with an ascending sequence when interaction between the seams is assumed.

To sum up, when there are thin interburden layers with thin bedrock layers, or if the working panel is located close to a water body, mining in ascending sequence is recommended. The WCFZ will be smaller and there will be less stress concentration. In this case, roof support, such as backfilling, may be required since excavation of the seams in an ascending sequence may cause more subsidence of the overburden.

When the interburden layers are thick, then a descending sequence is recommended because the WCFZ will be smaller when there is no apparent interaction between the seams, and the overburden can be better controlled. Attention needs to be paid to the concentration of stress in the pillars to allow the lower seam to be mined.

The formulae (Eq. 1 and Table 1) that was used for calculating the heights of the overburden failure due to mining of two seams does not consider the effects of the mining sequence. This study has shown that the overburden failure heights are different with ascending and descending sequences.

\section{Principal Stress and Subsidence (Vertical Displacement)}

According to Figs. 6, 7, and Supplemental Figs. 7 and 9 (see the squares of each figure), the distribution of the concentration of the principal stress around the stope (without the pillars) is negatively correlated with subsidence (vertical displacement). This means that when the principal stresses are concentrated around the stope, the subsidence of the entire overburden above this area will be relatively small.

When the situation changes to descending mining with no apparent interaction and mining single seam with an obvious interaction [Supplemental Figs. 6, 8, 10, 11 (see the squares of each figure)], the distribution of the principal stresses is positively correlated with the vertical subsidence. When there is a concentration of stress, the vertical subsidence above this entire area will have be relatively large. Consequently, the concentration of stress at the working panel should be measured to determine if an overburden will have a larger subsidence area, because this is likely where overburden failure may occur.

\section{Conclusions}

In this paper, mining interactions and overburden failure as a result of mining coal seams in close proximity in ascending and descending sequences under a large water body were discussed. Two case studies were examined using empirical formulae, scale model tests, and numerical simulations. We found that the heights of the overburden failure determined by the three methods were in a good agreement, which affirmed the reliability of the numerical simulations.

Stress concentrations associated with mining of the two seams in either an ascending or descending sequence were compared. In the former, the stress was mostly concentrated in the pillars and middle of the lower stope, while in the latter, it was mostly concentrated in the pillars and the front of the upper stope. This also affected the development and distribution of fractures in the overburden: fractures were generated above both the stope and pillars when the lower seam was mined first, while extensive fracture development occurred above the pillars when the upper seam was mined first.

The effects of seam interaction on overburden failure were examined with both mining sequences and different interburden thicknesses. The maximum horizontal and vertical stresses were 28.6 and $11.1 \%$ less with a descending sequence than with an ascending sequence when the modeling assumed no apparent interaction. However, when the interburden was thinner (causing interaction), the horizontal stress decreased by $14.3 \%$, but the vertical stress increased by $36 \%$ with a descending sequence.

The ratios of the heights of the water-conducting fractured and caving zones with the cutting height both increased with reduced interburden thickness (seam interaction) in each mining sequence. A larger increase of the ratios was observed with a descending sequence because the interaction between the two seams influenced the concentration of stress and development of fractures more. It also affected the 
vertical displacement with an ascending sequence. Therefore, mining the lower seam first is recommended when the geological conditions include thin interburden layers and thin bedrock layers, while mining in a descending sequence is recommended for thick layers of interburden. Moreover, a positive correlation was found between the principal stress concentration and the overburden subsidence above the area of concentrated stress when mining the upper seam first with a thick interburden or a single seam with an obvious interaction. A negative correlation was found between mining in an ascending sequence with a thick interburden (no apparent interaction) and mining two seams with an obvious interaction, which can be used to predict where overburden failure will occur.

Acknowledgements The authors thank the National Key R\&D Program of China (Grant 2017YFC0804101) and the Priority Academic Program Development (PAPD) of Jiangsu Higher Education Institutions for their financial support of this work.

Open Access This article is distributed under the terms of the Creative Commons Attribution 4.0 International License (http://creativecommons.org/licenses/by/4.0/), which permits unrestricted use, distribution, and reproduction in any medium, provided you give appropriate credit to the original author(s) and the source, provide a link to the Creative Commons license, and indicate if changes were made.

\section{References}

Akinkugbe OO (2004) A simple two-dimensional boundary element program for estimating multiple seam interaction, Master Dissertation. West Virginia University, Morgantown

Alvarez R, Ordonez A, Miguel ED, Loredo C (2016) Prediction of the flooding of a mining reservoir in NW Spain. J Environ Manag 184:219-228

Chekan G, Listak J (1993) Design practices for multiple-seam longwall mines. US Bureau of Mines IC 9360, Pittsburgh

Fan YS, Zhang SY (2015) Analogue simulation for overlying strata movement rule of lower layer in mining the close coal seams. J Liaoning Tech Univ Nat Sci 34(8):887-891 (in Chinese)

Feng GR, Wang XX, Kang LX (2008) A probe into "mining technique in the condition of floor failure" for coal seam above longwall goafs. J Coal Sci Eng 14(1):19-23

Jiang YD, Meng L, Zhao YX, Pan L, Lei Y (2012) The feasibility research on ascending mining under the condition of multidisturbances. Procedia Environ Sci 12:758-764

Jin K, Cheng YP, Wang W, Liu HB, Liu ZD, Zhang H (2016) Evaluation of the remote lower protective seam mining for coal mine gas control: a typical case study from the Zhuxianzhuang coal mine, Huaibei coalfield, China. J Nat Gas Sci Eng 33:44-55

Li P, Qian H, Wu J, Zhang Y, Zhang H (2013) Major ion chemistry of shallow groundwater in the Dongsheng coalfield, Ordos Basin, China. Mine Water Environ 32(3):195-206

Li P, Qian H, Howard KWF, Wu J (2015) Building a new and sustainable "Silk Road economic belt". Environ Earth Sci 74(10):7267-7270

Li P, Li X, Meng X, Li M, Zhang Y (2016) Appraising groundwater quality and health risks from contamination in a semiarid region of northwest China. Expo Health 8(3):361-379
Li P, Qian H, Zhou W (2017) Finding harmony between the environment and humanity: an introduction to the thematic issue of the Silk Road. Environ Earth Sci 76(3):105

Liang S, Li XH, Mao YX, Li CJ (2013) Time-domain characteristics of overlying strata failure under condition of longwall ascending mining. Int J Min Sci Technol 23:207-211

Liu XS, Tan YL, Ning JG, Wang J (2016) Fracture evolution and accumulation and dissipation law of energy during ascending mining. Geotech Geol Eng 34:647-655. https://doi.org/10.1007/ s10706-015-9973-6

Loveday PF, Atkins AS, Aziz NI (1983) The problems of Australian underground coal mining operations in water catchment areas. Int J Mine Water 2(3):1-15

Ma L, Xiao Y, Wang ZP, Wang HQ, Wen H (2007) Study on speedy emergent controlling technology and equipment of coal seam fire. In: Wang CQ, Guo WJ, Cheng JL, Zou DH (eds) Mine hazards prevention and control technology. Science Press, Beijing, pp 123-129

Ma L, Wen H, Xiao Y, Wang QH, Wang ZP, Zhang GW (2009) Analysis on air-leakage law of goaf in condition of ascending mining for top-coal caving. J Coal Sci Eng 15(1):81-84

Mark C (2007) Multiple-seam mining in the United States: background. In: Mark C, Tuchman RJ (eds) Proceedings of new technology for ground control in multiple seam mining. National Institute for Occupational Safety and Health, Pittsburgh, pp 3-14

Meng ZP, Shi XC, Li GQ (2016) Deformation, failure and permeability of coal-bearing strata during longwall mining. Eng Geol 208:69-80

Rubio RF (1986) Water problems in Spanish coal mining. Int J Mine Water 5(3):13-28

Singh TN, Singh B (1985) Model simulation study of coal mining under river beds in India. Int J Mine Water 4(3):1-10

Singh AP, Gupta PK, Khandelwal M (2013) Prediction of sea water intrusion for mining activity in close precincts of sea shore. Springer Plus 2:417-426

State Administration of Work Safety, State Administration of Coal Mine Safety, National Energy Administration, National Railway Administration of the People's Republic of China (2017) Regulations for coal mining and coal pillar leaving under building, water, railway and main shaft and tunnel. China Coal Industry Press, Beijing (in Chinese)

Sui WH, Xu ZM (2013) Risk assessment for coal mining under sea area. New Front Eng Geol Environ 9:199-202

Sui WH, Hang Y, Ma LX, Wu ZY, Zhou YJ, Long GQ, Wei LB (2015a) Interactions of overburden failure zones due to multiple-seam mining using longwall caving. Bull Eng Geol Environ 74:1019-1035

Sui WH, Zhang DY, Cui ZDC, Wu ZY, Zhao QJ (2015b) Environmental implications of mitigating overburden failure and subsidence using paste-like backfill mining: a case study. Int J Min Reclam Environ 29(6):521-543

Wang WX, Hu W, Liang YK (2013) Experimental investigation for water flowing fractured zone due to coal mining under sea area. New Front Eng Geol Environ 9:207-209

Wang C, Zhang NC, Han YF, Xiong ZQ, Qian DY (2015) Experiment research on overburden mining-induced fracture evolution and its fractal characteristics in ascending mining. Arab J Geosci 8:13-21

Wu J, Sun Z (2016) Evaluation of shallow groundwater contamination and associated human health risk in an alluvial plain impacted by agricultural and industrial activities, mid-west China. Expo Health 8(3):311-329

Xu ZM, Sui WH (2013) Statistical prediction of overburden failure due to coal mining under sea area. New Front Eng Geol Environ $9 \cdot 255-258$ 
Xu MG, Yang K, Yan SY (2014) Numerical simulations of evolution stress from pressure relief mining of close coal seam group. J Liaoning Tech Univ Nat Sci 33(9):1159-1164 (in Chinese)

Zhang YX, Tu SH, Bai QS, Li JJ (2013) Overburden fracture evolution laws and water-controlling technologies in mining very thick coal seam under water-rich roof. Int J Min Sci Technol 23(5):693-700
Zipf RK (2005) Failure mechanics of multiple seam mining interactions. In: Proceedings of 24 th international conference on ground control in mining, pp 93-107 